\title{
The morphology and affinities of Skania fragilis (Arthropoda) from the middle Cambrian Burgess Shale
}

\author{
DAVID A. LEGG
}

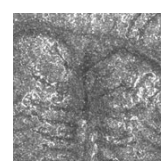

\begin{abstract}
The enigmatic arthropod Skania fragilis, from the middle Cambrian (Series 3, Stage 5) Burgess Shale Formation (Yoho National Park, British Columbia, Canada), is redescribed based on 14 new specimens reposited at the Royal Ontario Museum. These specimens provide a clearer picture of the morphology of this taxon and help to resolve conflicting opinions regarding potential homology of particular features. Specifically, the anchor-shaped anterior, which has been compared to a similar structure in the putative Precambrian arthropod Parvancorina, is shown to represent an anterior cephalic doublure with features comparable to the mediolateral spines of marrellids, such as Marrella. Beyond a vaguely cordiform outline, no other features are shown to be shared between Skania and Parvancorina, weakening claims that crown-group arthropods were present in the Neoproterozoic. The removal of these taxa from Arthropoda is in keeping with recent molecular clock analyses, which demonstrate a Cambrian diversification of Euarthropoda. A phylogenetic analysis resolved Skania as the most basal member of Acercostraca, a clade of marrellomorphs including Vachonisia and Xylokorys, united by the presence of a cordiform dorsal shield. Similarities between these taxa and marrellids may indicate that the elongate posterior spines of Marrella and related taxa, and the dorsal shield of acercostracans have a common origin akin to the carapace anlagen of extant crustaceans. - Key words: marrellomorph, carapace formation, Burgess Shale.
\end{abstract}

LEGG, D.A. 2015. The morphology and affinities of Skania fragilis (Arthropoda) from the middle Cambrian Burgess Shale. Bulletin of Geosciences 90(3), 509-518 (5 figures, 2 online appendices). Czech Geological Survey, Prague. ISSN 1214-1119. Manuscript received September 1, 2014; accepted in revised form April 21, 2015; published online May 27, 2015; issued September 30, 2015.

David A Legg, Oxford University Museum of Natural History, Parks Road, Oxford OX1 3PW, UK; david.legg@oum.ox.ac.uk

Since its original description in the posthumous manuscript of Walcott (1931), discussion regarding the affinities of the enigmatic arthropod Skania fragilis, from the middle Cambrian (Series 3, Stage 5) Burgess Shale Formation of British Columbia, has been equivocal. Although originally comparisons were made to Marrella, Burgessia, and Naraoia, notes associated with the original publication indicate that Walcott considered Skania to be a trilobite (Resser in Walcott 1931). This interpretation was followed by Størmer (1944) amongst others (e.g. Hupé 1953), who, based on the pliable nature of its exoskeleton, suggested it might represent a larval stage presumably of another Burgess Shale trilobite. Harrington (1968, p. O99), however, dismissed trilobite affinities for Skania, noting "[it] does not resemble any known trilobite meraspis", although an alternative affinity was not proffered. A similar conclusion was also reached by Delle Cave \& Simonetta (1975). They undertook a restudy of the 29 specimens assigned to $S$. fragilis by Walcott (1931) and concluded that only eight specimens were valid, none of which showed unequivocal arthropod features such as arthropodized appendages and segmentation. Instead, Delle Cave \& Simonetta (1975) emphasised similarities between Skania and the Precambrian Parvancorina, particularly pertaining to the putative guts of these taxa which were both considered to be anchor-shaped. Glaessner (1980) reaffirmed arthropod affinities for Parvancorina based in part on similarities to marrellomorphs, such as the shield-like carapace of Vachonisia. He was, however, sceptical of a close relationship between Parvancorina and Skania, a view not shared by many later workers (e.g. Gehling 1991, Conway Morris 1993, Simonetta \& Insom 1993). In a subsequent phylogenetic analysis, Waggoner (1996) resolved Parvancorina as a stem-group arthropod, but considered Skania to represent a "true" arthropod due to its resemblance to purported protaspids of Naraoia from the Lower Cambrian Chengjiang biota (Hou et al. 1991). These supposed naraoiid larva where later assigned to their own genus and species, Primicaris larvaformis (Zhang et al. 2003), which, along with Parvancorina and Skania, were placed in the Parvancorinomorpha, as were other potential Precambrian arthropods and tentatively the Devonian Vachonisia (Lin et al. 2006). 
This clade was thought to represent an incipient stage in the development of arachnomorph tagmosis. Similar topologies have not been recovered in recent phylogenetic analyses (Legg et al. 2012, 2013), which have instead resolved marrellomorphs, including Skania and Vachonisia, as stem-lineage mandibulates, although admittedly Parvancorina and other putative Precambrian arthropods were not included in these analyses. To resolve this phylogenetic confusion new specimens of Skania fragilis are described herein. These specimens are used to build a more complete picture of its morphology, which will aid in determining its phylogenetic affinities.

\section{Materials and methods}

The specimens deposited at the ROM were examined using a Nikon SMZ1500 binocular microscope with a drawing tube attached. All specimens, including the holotype, were photographed using a Canon EOS 5D Mark II digital SLR camera equipped with Canon macro lenses (EF $100 \mathrm{~mm}$ f/2.8 Macro and MP-E $65 \mathrm{~mm} \mathrm{f/2.8} \mathrm{1-5x} \mathrm{Macro} \mathrm{Photo)}$ with a polarizing filter. A variety of lighting conditions were used, however the best results were obtained when using low-angle cross polarized light with specimens immersed in water (Schaarschmidt 1973, Bengtson 2000, Crabb 2001).

\section{Phylogenetic analysis}

Although Skania fragilis has been included in prior phylogenetic analyses of arthropods (e.g. Legg et al. 2012, 2013), character coding was based solely on previous descriptions and interpretations of this taxon, particularly those of Delle Cave \& Simonetta (1975), and Lin et al. (2006). This taxon was thus recoded into an updated version of the Legg et al. (2013) data set (with subsequent modifications from Siveter et al. 2014), based on the examination and interpretation of new material presented herein, as were other non-marrellid marrellomorphs, namely S. sundbergi Lin et al. 2006, Primicaris Zhang et al. 2003, an undescribed acercostracan from Morocco (Van Roy et al. 2010), and the acercostracans Xylokorys Siveter et al. 2007, and Vachonisia (Kühl et al. 2008). A single character, "fusion of paratergal fold into a dorsal shield" (formerly character 69 of Legg et al. 2013), was removed from the original data set to account for observations made herein resulting in a total data set of 315 taxa and 752 characters (see online supplementary material).

The data set was converted into NEXUS file format (available as online supplementary material) and analysed using TNT v. 1.1. (Goloboff et al. 2008). All characters were treated as non-additive and weighted using both equal character weighting and implied weighting with a variety of concavity constants $(k=2,3,10)$. Most Parsimonious trees (MPTs) were found using New Technology search options with 100 Random Addition Sequences using Parsimony Ratchet (Nixon 1999), Sectorial Searches, Tree Drifting and Tree Fusing (Goloboff 1999).

\section{Systematic palaeontology}

Unnamed rank Marrellomorpha Beurlen, 1930

Order Acercostraca Lehmann, 1955

Emended diagnosis. - Arthropod possessing an extensive cordiform carapace covering all appendages (emended from Tasch 1969).

Included taxa. - Skania Walcott, 1931, Primicaris Zhang et al., 2003, "Skania" sundbergi Lin in Lin et al., 2006, and Vachonisiidae Tasch, 1969.

\section{Plesion (genus) Skania Walcott, 1931}

Type species. - Skania fragilis Walcott, 1931 (by monotypy).

Emended diagnosis. - Arthropod with a cordiform carapace with an anterior doublure bearing lateral spines, and possessing elongate spines and slight serration on its postero-lateral edge, plus crescent-shaped anterior diverticulae extending into elongate lateral diverticulae with medially projecting secondary rami (emended from Lin et al. 2006).

General dimensions. - Specimens range in size from $7.5 \mathrm{~mm}$ (ROM 63029) to $13.5 \mathrm{~mm}$ (ROM 63027, 63032, 63034, and 63035), measured sagitally, and between $9 \mathrm{~mm}$ (USNM 83950) and $11.5 \mathrm{~mm}$ (ROM 63027 and 63032), measured transversely. Despite this variation in size, all specimens retain a width to length ratio of $1: 1.2$. The posterior spines measure between 10 and 15 percent of the total body length, except in the smallest individual, ROM 63029 , in which they account for 20 percent of the total body length.

Remarks. - The diagnosis of Lin et al. (2006) was based, in part, on the assignment of "Skania" sundbergi to this genus, however, this taxon differs significantly from S. fragilis, perhaps indicating they should be placed in separate genera. For this reason the diagnosis of Skania is restricted to $S$. fragilis, pending further study of "S." sundbergi. 

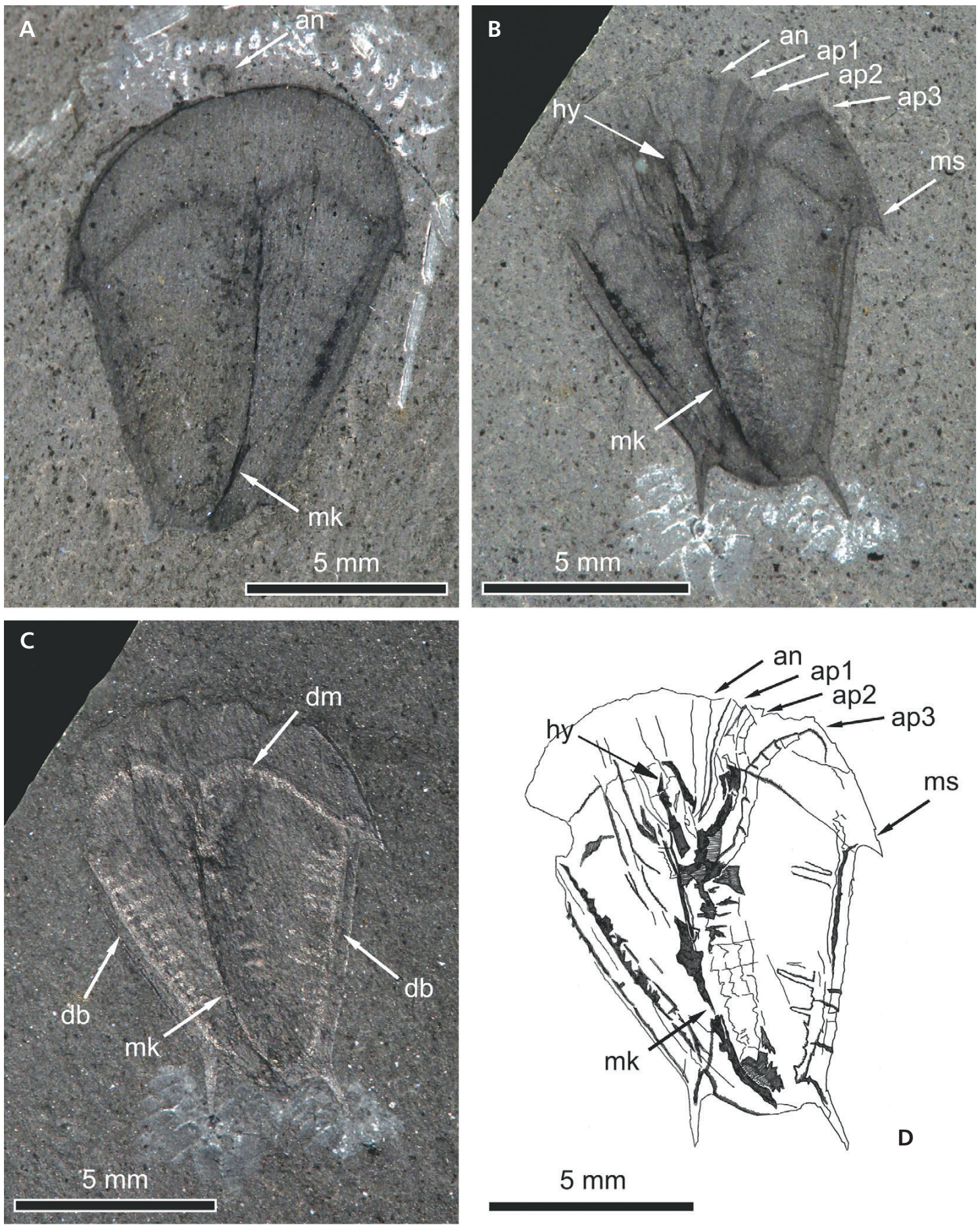

$5 \mathrm{~mm}$

Figure 1. Holotype of Skania fragilis Walcott, 1931 (USNM 83950). A, B - part and counterpart photographed using cross polarised light. • C - counterpart photographed using plain polarised light. $\bullet$ D - camera lucida drawing of the counterpart. Abbreviations: an - antenna, ap 1-3 - appendages 1-3, $\mathrm{db}$ - doublure-like structure, $\mathrm{dm}$ - posterior margin of the doublure, hy - hypostome, mk - medial keel, $\mathrm{ms}$ - mediolateral spine.

\section{Specimens}

Fifteen specimens of Skania fragilis were examined: 14 undescribed specimens reposited at the Royal Ontario Museum (ROM), Toronto, Canada, and the holotype reposited at the Smithsonian National Museum of Natural History, Washington DC, USA. All material was excavated from exposures of the middle Cambrian (Series 3, Stage 5, Bathyuriscus-Elrathina Zone) Burgess Shale Formation situated along Fossil Ridge in Yoho National Park (British 
Columbia, Canada). The holotype, USNM 83950 (Fig. 1), was recovered from the Walcott Quarry exposure (formerly USNM locality 35k) of the Walcott Quarry Shale Member (Pagetia bootes Subzone). Of the remaining specimens, 11 (ROM 60752, 63022, 63026, and 63028-63035; Figs 2C, E-H, 3) originated from the Raymond Quarry exposure of the Raymond Quarry Shale Member (Pagetia walcotti Subzone), and three (ROM 63023, 60325, and 63027; Fig. 2A, B, D) from the associated talus. Other specimens assigned to $S$. fragilis, reposited at the USNM and ROM, were also examined but no diagnostic characteristics where observed which might justify assignment to this taxon.

\section{Morphological interpretation of Skania fragilis}

Perhaps the most conspicuous feature of Skania fragilis is the cordiform dorsal shield (Figs 1-4). The exact composition of the dorsal shield has been unclear, specifically whether it is formed by the fusion of trunk tergopleurae, or represents a posterior outgrowth of the cephalic shield, i.e. a carapace (sensu Olesen 2013). Most previous works (e.g. Walcott 1931, Glaessner 1980, Lin et al. 2006, Rak et al. 2013) have favoured a trunk tergite derivation for the dorsal shield. Walcott (1931) thought the posterior dorsal shield was formed via the fusion of 14 or 15 segments whose borders were still evident. However, it was a lack of clear segmentation, which led Delle Cave \& Simonetta (1975) to conclude Skania was not an arthropod. Nearly all specimens (Figs 2B-E, G, H, 3), including the holotype (Fig. 1), show delineations near the edge of the dorsal shield, which Walcott (1931) may have mistaken for segmental boundaries. However, these delineations are not part of the tergal exoskeleton and instead form part of a diverticulate network (Figs 3, 4). Lin et al. (2006) also suggested that the dorsal shield was formed of a single element and not composed of fused segments expressed as dorsal tergites, however, they did consider it essentially bipartite with an anterior "cephalic area" bearing genal spines and covering the antennae, and a fused posterior "trunk region" covering all other appendages. In their cladogram (Lin et al. 2006, fig. 9) the parvancorinomorphs, including Skania, were placed as sister-taxon to arachnomorphs based on the shared presence of a "pleural field", the implication being that the dorsal shield was homologous to arachnomorph tergites, although articulation was a later acquisition in the latter group. The so-called "cephalic area" of Lin et al. (2006), is herein interpreted as an anterior cephalic doublure, akin to that of artiopodans. USNM 83950 (Fig. 1C), ROM 63026 (Fig. 2C), and ROM 60752 (Fig. 3A) demonstrate that a delineation (or the posterior margin of the doublure, labelled "dm"), is present anterior of the diverticulae and first appendage pair (contra Lin et al. 2006). The association of the lateral spines with the anterior cephalic doublure (Figs 1, 2B, E, 3A, C-E) makes them unlike genal spines, as they have previously been identified (e.g. Walcott 1931, Lin et al. 2006), which are usually post-appendicular and associated with the posterolateral margins of the cephalon (Harrington 1968). Instead, they are more comparable to the mediolateral spines of marrellid marrellomorphs (Rak et al. 2013), which are pre-appendicular (García-Bellido \& Collins 2006), and form part of a crescent-shaped anterior cephalon.

The extensive diverticulae of Skania have received considerable attention (e.g. Walcott 1931, Størmer 1944, Hupé 1953). In the majority of specimens the anterior diverticulae arch laterally in a contiguous line with the posterior boundary of the doublure (e.g. Fig. 3C). These lateral diverticulae originate from a medial triangular node (Fig. 3F), and continue posteriorly with the outer margin running parallel to the lateral margins of the dorsal shield (Fig. 3). The outer margins of these diverticulae give the impression of a marginal rim bordering the dorsal shield, however, a distinctive rim is lacking as evidenced by specimens lacking distinctive diverticulae, in particular ROM 63023 (Fig. 2A), however, a doublure-like structure can be observed in some specimens, e.g. USNM 83950 (Fig. 1) and ROM 63029 (Fig. 3C). Each lateral diverticula possesses a series of secondary channels which project perpendicular to the main diverticular axis towards the medial axis of the specimen (Fig. 3). The most anterior secondary diverticulae show noticeable curvature towards the anterior of the specimen (e.g. Fig. 3A, C) and may show additional branching (Fig. 3D). A putative gut runs from the triangular node to the posterior margin of the dorsal shield (Fig. 3F). The position of the mouth is uncertain but was presumably located at the posterior end of the hypostome (Fig. 1B).

The nature of the lateral diverticulae is unclear. Although they seem to connect to a putative gut structure it is possible they are associated through superposition rather than genuinely connected. ROM 63022 (Fig. 3B) shows differential preservation of the diverticulae and the putative gut, the latter is preserved in noticeable relief whereas the diverticulae are not. Furthermore, when some specimens were photographed using polarised light the lateral diverticulae and appendages became reflective, whereas the putative gut remained dull (Figs 1A, 3F). A reflective film is also preserved around the main body axis (Figs 2C, 3F). This area, and associated material in the appendages may indicate a cardiovascular nature, however, it resembles no other arthropod circulatory system. The diverticular network shows similarities to the ramified gut diverticulae of Burgessia (Hughes 1975) and Naraoia (Vannier \& Chen 2002). Such diverticulae are restricted to the cephalic regions of these taxa, which in Burgessia shows considerable overlap of the trunk somites (Hughes 

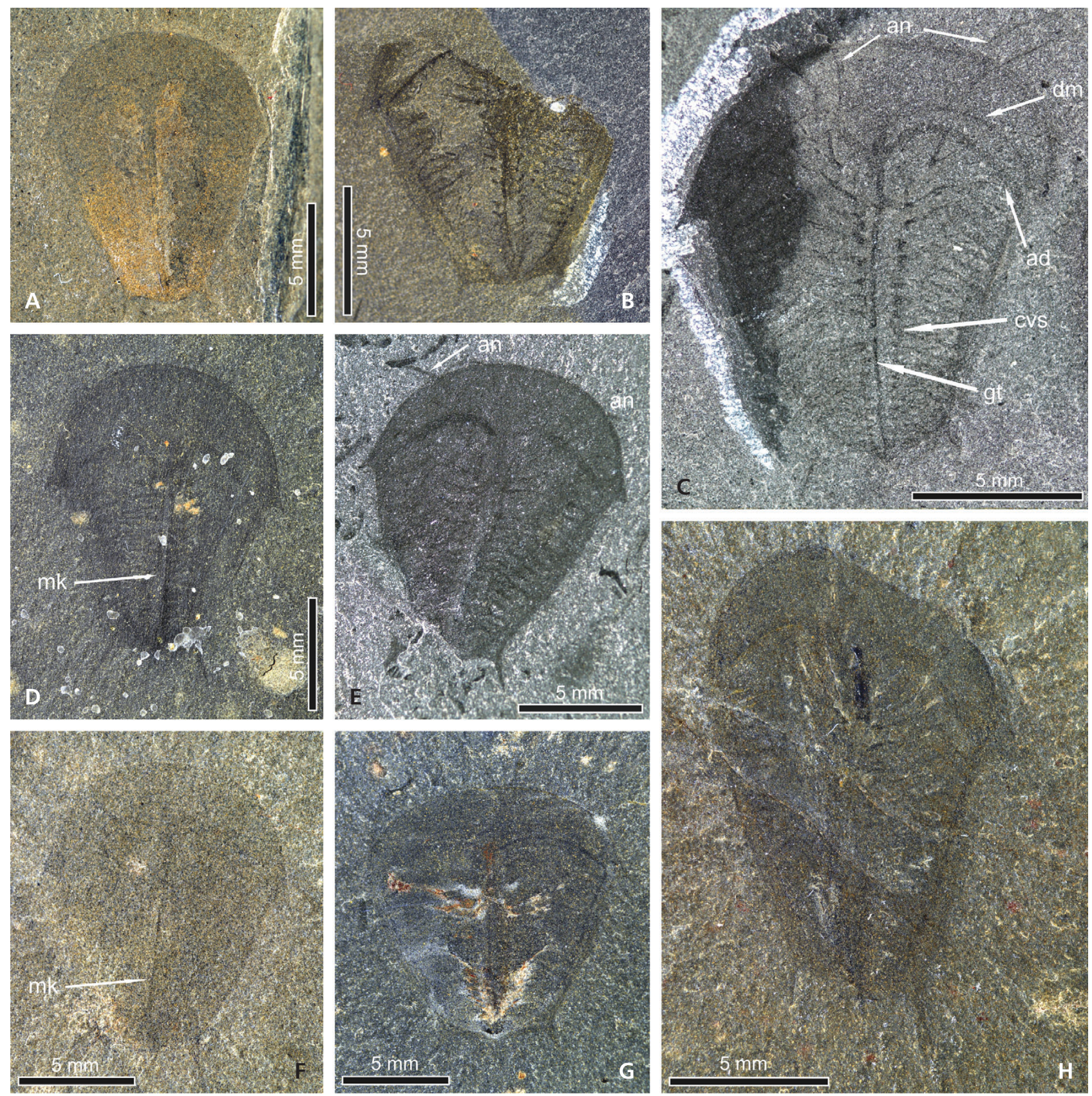

Figure 2. New specimens of Skania fragilis Walcott, 1931, from Raymond Quarry. All photographed using cross-polarised light. • A - ROM 63023. - B - ROM 63025. • C - ROM 63026. • D - ROM 63027. • E - ROM 63028. • F - ROM 63032. - G - ROM 63033. • H - ROM 63035. Abbreviations: $\mathrm{ad}$ - anterolateral diverticula, an - antenna, cvs - cardiovascular system, dm - posterior margin of the doublure, gt - gut, mk - medial keel-like structure.

1975), akin to a crustacean carapace (Olesen 2013). The similar arrangement in Skania may indicate that the dorsal shield represents a carapace that has become fused to the trunk, much as it is in extant malacostracans (Olesen 2013), rather than the fused pleurotergites of the trunk. Further support for this hypothesis comes from comparisons with other taxa bearing a dorsal shield, particularly Vachonisia, which early in ontogeny possesses a rounded dorsal shield, which becomes more cordiform and develops considerable posterior expansions later in development (Kühl et al. 2008). A similar mode of development is shown by the carapace of the notostracan Triops cancriformis, which also develops considerable posterior expansions during later growth stages (Olesen \& Møller 2014).

The morphology of the appendages of Skania has had only vague mention in previous works (e.g. Walcott 1931, Lin et al. 2006). These studies recognised putative antennae in the holotype and poorly preserved thoracic 

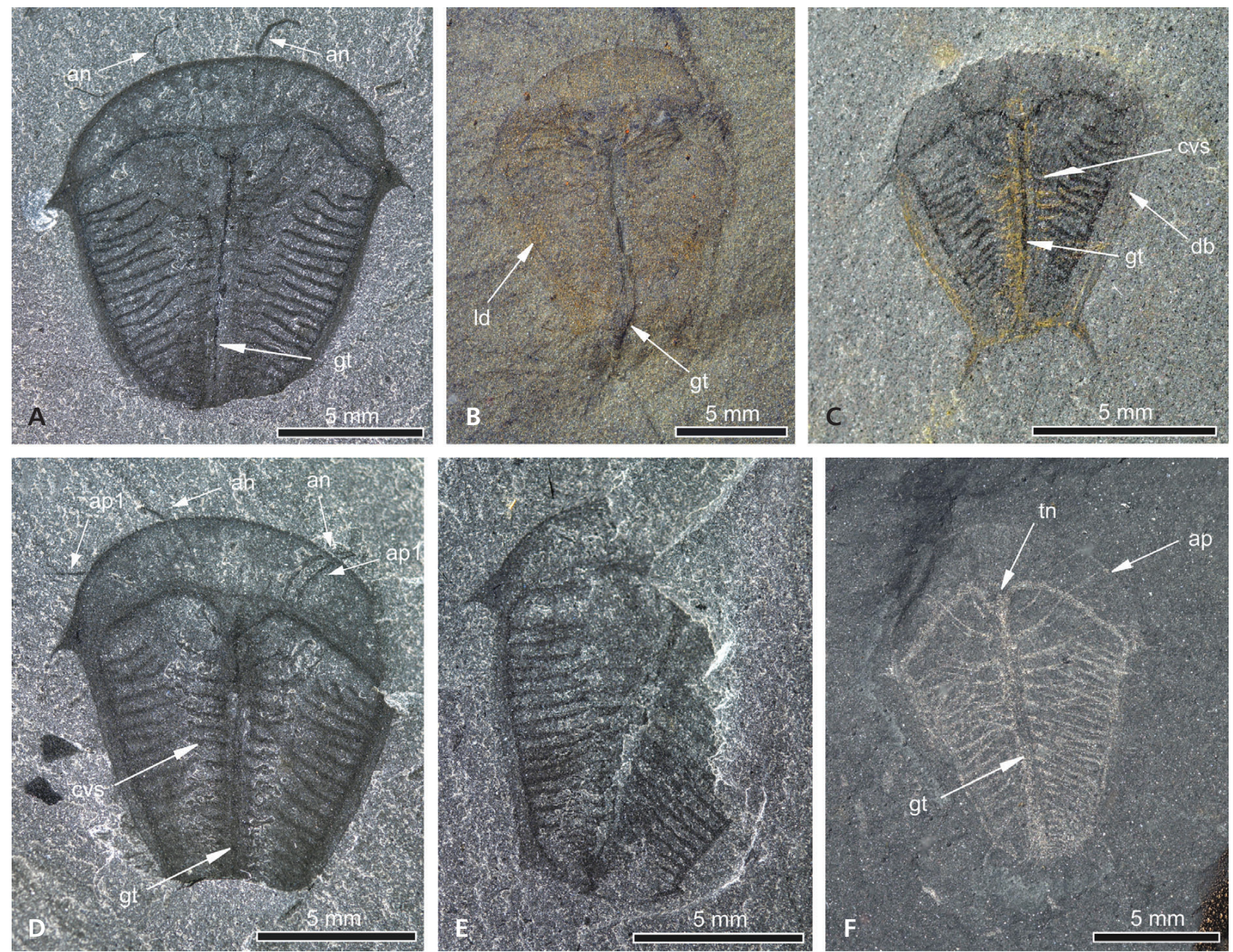

Figure 3. Digestive structures in new specimens of Skania fragilis Walcott, 1931. • A - ROM 60752. • B - ROM 63022. C - ROM 63029. • D - ROM 63030. • E - ROM 63031. • F - ROM 63034. Abbreviations: ap - appendage, cvs - cardiovascular system, db - doublure-like structure, gt - gut, ld - lateral diverticula, tn - triangular node.

endopods. In fact, Skania appears to possess two sets of differentiated appendages. The anterior appendages are elongate and sigmoidal, extending beyond the anterior boundary of the cephalon (Figs 1B, 2C, 3A, D, F). At least five pairs are present, the anterior four of which abut an elongate labrum-like structure (Fig. 1B). Podomere boundaries are best observed in the holotype, in which the anterior-most appendage pairs possess small, sub-quadrate podomeres (Fig. 1A), and the more posterior sigmoidal appendages possess elongate, subrectangular podomeres (Fig. 1B). The arrangement of the anterior appendages, particularly their sigmoidal nature resembles the cephalic exopods of other acercostracans, particularly Vachonisia and Xylokorys. The posterior trunk appendages are differentiated from the cephalic appendages in being shorter, i.e. not extending beyond the carapace margins, and they show a lesser degree of curvature (Fig. 3A, D). Individual podomeres could not be observed.

\section{Discussion}

\section{The status of Precambrian "arthropods"}

Skania has frequently been linked to so-called Precambrian "arthropods", particularly Parvancorina (Gehling 1991, Simonetta \& Insom 1993, Lin et al. 2006), and thus potentially represents a late surviving member of a Precambrian body plan (Conway Morris 1993). Few phylogenetic analyses have possessed the taxon coverage to explore possible relationships of these taxa, as those including a variety of putative Precambrian arthropods have excluded Skania (e.g. Waggoner 1996), or vice versa (e.g. Legg et al. 2012, 2013). A notable exception is the phylogenetic analysis of Lin et al. (2006), which included both Skania, and a handful of Precambrian "arthropods", namely Mialsemia (= Bomakellia sensu Dzik 2002), Vendia, Praecambridium, and Parvancorina. Such limited taxon sampling was 
guaranteed to resolve Skania as an ingroup parvancorinomorph and therefore does not represent a reliable test of affinities. The singular ingroup taxon, Parvancorinomorpha encompasses Skania, Vendia, Praecambridium, and Parvancorina, and was erected based on the shared presence of an anchor-shaped anteromedial ridge (Lin et al. 2006). The validity of this group therefore relies on reliable homology of these anchor-like structures. In Skania this anchor is composed of the anterior doublure and the medial keel on the carapace. This keel is weakly developed in S. fragilis (Figs 1, 2D) but more prominent in "S." sundbergi, however it is not attached to the anterior doublure (Lin et al. 2006, fig. 2e-h). By contrast the anchor of Parvancorina is set back from the "anterior" margin and is therefore unlikely to be homologous to the doublure-like structure in Skania. Once we remove this character the only other character linking Skania and Parvancorina is a cordiform outline, however, this feature in Parvancorina shows considerable ontogenetic and interspecific variation (Naimark \& Ivantsov 2009), and despite previous claims (Lin et al. 2006), does not show a similar growth trajectory to $S k a$ nia (Naimark \& Ivantsov 2009).

Analyses linking these taxa also relied heavily on the identification of appendages in Parvancorina (Glaessner 1980). These appendages were reported as attaching to the anterior anchor-shaped ridge (Glaessner 1980), unlike any known arthropod, which instead typically show considerable antero-posterior alignment of appendages and segments (Ortega-Hernández \& Brena 2012), as seen in Skania and non-Precambrian "parvancorinomorphs". Such patterning is caused by antero-posterior gene expression domains that show little or no relative lateral displacement (Ortega-Hernández \& Brena 2012). This also weakened likely relationships between arthropods and taxa possessing glide reflection symmetry such as Vendia, and Praecambridium (Ivantsov 2001).

The removal of Precambrian "arthropods" from Arthropoda is in keeping with recent molecular clock estimates that indicate a Cambrian, rather than Precambrian, diversification of crown-group arthropods (Lee et al. 2013, Rota-Stabelli et al. 2013).

\section{The affinities of Skania and relationships within Marrellomorpha}

Phylogenetic analysis with equal character weighting resulted in 14 Most Parsimonious Trees (MPTs) of 1839 steps $(\mathrm{CI}=0.518 ; \mathrm{RI}=0.873)$, and implied weighted analyses with a concavity constant of two, three, and 10 produced 12 MPTs of 173.95755 steps $(\mathrm{CI}=0.515$; $\mathrm{RI}=0.871)$, 25 MPTs of 140.71591 steps $(\mathrm{CI}=0.515 ; \mathrm{RI}=0.871)$, and 19 MPTs of 63.35458 steps $(\mathrm{CI}=0.517$; RI $=0.872)$, respectively.

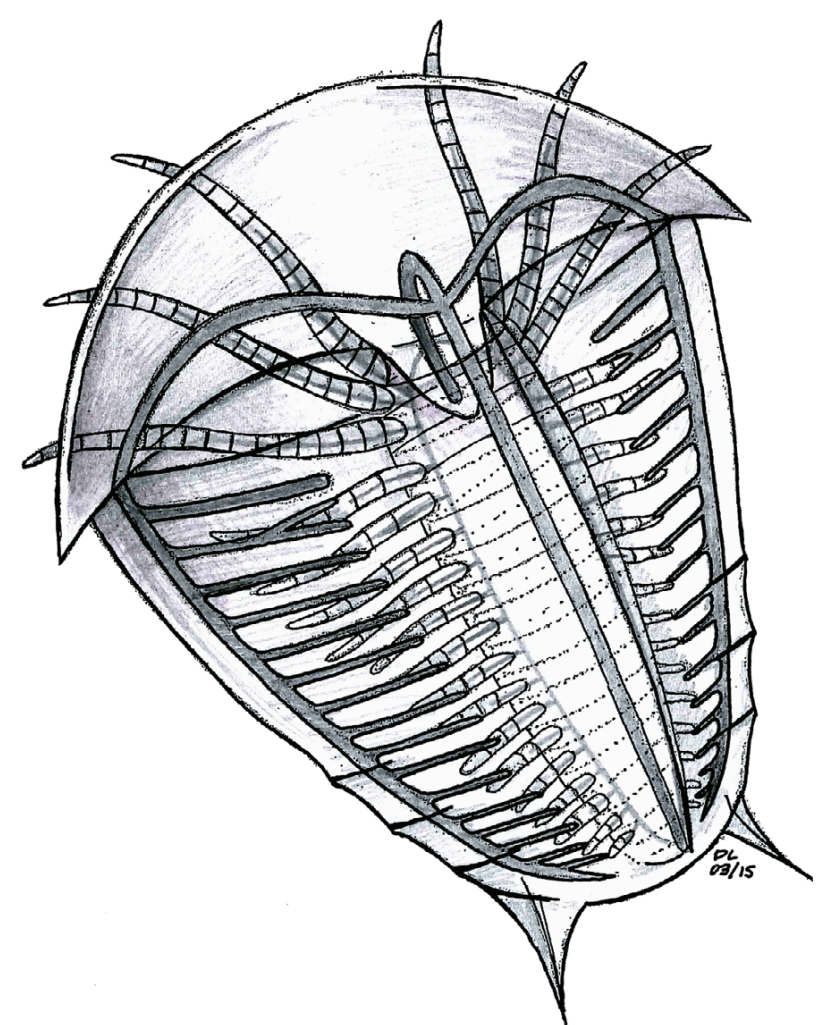

Figure 4. A reconstruction of Skania fragilis showing internal diverticular network.

Both inter- and intrarelationships of Skania and the marrellomorphs were consistent over all iterations of the data set (Fig. 5). Skania fragilis resolved as the basal most member of a clade composed of Primicaris, "S." sundbergi, and a polytomy including Vachonisia, Xylokorys, and an undescribed taxon from the Ordovician of Morocco (Van Roy et al. 2010). These taxa were all assigned to Parvancorinomorpha by Lin et al. (2006), however, the exclusion of vendiomorphs, particularly Parvancorina, from this clade renders this clade, as originally intended, polyphyletic. It also seems appropriate to reserve this clade name for a group including its namesake. The name Acercostraca was originally proposed for Vachonisia alone (Lehmann 1955) and was subsequently expanded to include Xylokorys (Rak et al. 2013), based on the shared presence of a cordiform dorsal shield (Siveter et al. 2007, Kühl et al. 2008). Both genera were also included in the family Vachonisiidae (Rak et al. 2013). Herein I propose retaining Vachonisia, Xylokorys and potentially the undescribed Moroccan acercostracan in Vachonisiidae and expanding Acercostraca to include those marrellomorphs which resolved closer to Vachonisia and Xylokorys, than to Marrella, Furca and Mimetaster (collectively = Marrellida), and possess a cordiform dorsal shield. Although the shape of the dorsal shield was not included as a character in the current analysis, this clade was supported by two 


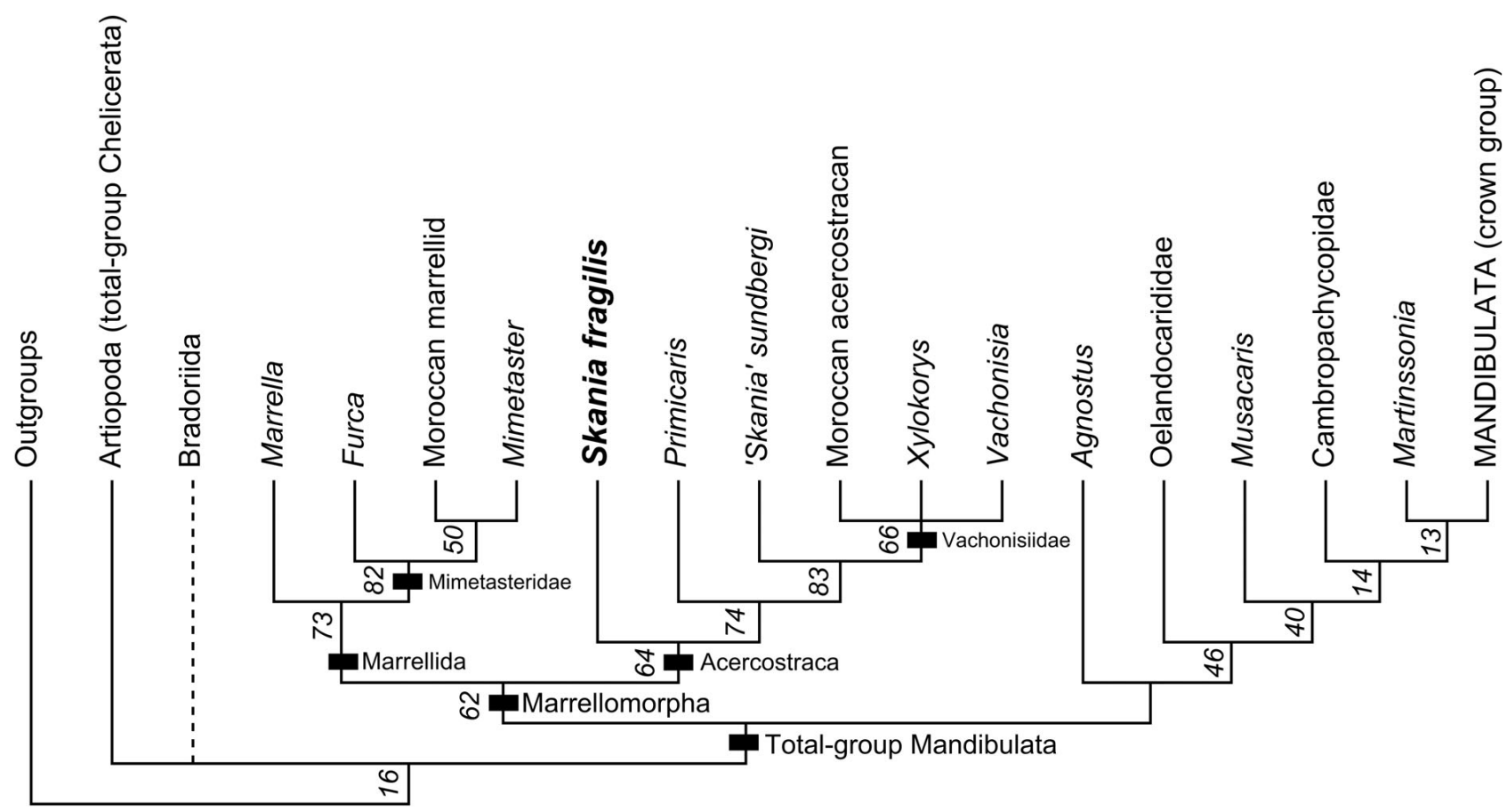

Figure 5. The phylogeny of marrellomorph arthropods as resolved in this study. The position of Bradoriida was unstable under different character weighting schemes, either resolving as sister-taxon to Artiopoda or total-group Mandibulata. Numbers associated with nodes are selected G/C frequency values produced under implied weighted searches with a concavity constant of three.

synapomorphies, the first of which was the presence of an expansive posterior carapace, and the second was the presence of an anterior cephalic doublure. Later taxa, namely Vachonisia and Xylokorys appear to have lost this doublure (Siveter et al. 2007, Kühl et al. 2008); this character resolved as a synapomorphy of Vachonisiidae, as did the presence of an anterior cephalic notch.

Skania fragilis, Primicaris and "S." sundbergi resolved as successive plesions of Vachonisiidae, indicating "S." sundbergi might not represent a species of Skania. Unlike S. fragilis and Primicaris, "S." sundbergi lacks spines on the posterior margins of its dorsal shield, a feature it shares with vachonisiids and which resolved as a synapomorphy of a "S." sundbergi + Vachonisiidae clade. "S." sundbergi also differs from $S$. fragilis in possessing an expansive marginal rim on the dorsal shield and a significantly raised axial region. A lack of these features may be autapomorphies of Skania fragilis, although in the current analysis their presence resolved as synapomorphies of a clade including all acercostracans to the exclusion of $S$. fragilis. Given the numerous differences between $S$. fragilis and "S." sundbergi it seems appropriate to refer the latter to a new genus, however, I refrain from doing so at this time, pending a formal restudy of "S." sundbergi.

A close relationship between the acercostrans and marrellids has been recognised for a long time (Stürmer \& Bergström 1976). In particular, workers have drawn atten- tion to similarities in abdominal and cephalic appendage morphology (Lehmann 1955, Stürmer \& Bergström 1976, Wills et al. 1998, Kühl et al. 2008). The monophyly of Marrellomorpha was supported in the current analysis by four synapomorphies: 1) a lack of paratergal pleurae, 2) an elongate trunk composed of more than 25 segments, 3) elongation of the cephalic exopods, and 4) the possession of rounded trunk endopod endites. The latter three characters were also used to support the monophyly of Marrellomorpha by Rak et al. (2013), and they also included two additional characters: 1) the presence of multisegmented trunk exopods with 2) medially directed filamentous setae. These characters are also present in many stem-mandibulates and in the current analysis resolved as a synapomorphy of total-group Mandibulata (all euarthropods closer to Mandibulata than Chelicerata). A similar relationship has been advocated by others (Waggoner 1996; Schram \& Koenemann 2004; Siveter et al. 2007; Legg et al. 2012, 2013).

Although a sister-taxon relationship between marrellids and acercostracans is little disputed (although see Hou \& Bergström 1997), they do show a number of features which are hard to homologise between these clades, particularly the nature of the dorsal cephalic shield which in marrellids possesses extensive mediolateral and posterolateral extensions, and in the acercostracans is expanded into a cordiform dorsal shield. The presence of lateral spines associated with a doublure in Skania increases 
similarities between acercostracans and marrellids, however, it does little to inform on the ancestral morphology of Marrellomorpha, specifically whether the plesiomorphic condition of the clade is the possession of elongate cephalic spines or an expansive dorsal shield. Simonetta \& Delle Cave (1981) hypothesised that the cephalon of marrellids evolved via the "erosion" of a Vachonisia-like carapace (although see Van Roy 2006 for a different hypothesis). A similar hypothesis is proposed herein. The presence of a posteriorly expansive carapace in other members of the mandibulate stem-lineage, such as Henningsmoenicaris (Haug et al. 2010) may indicate this represents the primitive condition of Marrellomorpha. If this is the case then the marrellids have secondarily lost their carapace. In extant crustaceans the carapace is formed from two posterior cephalic anlagen which fuse to form a shied like structure (Olesen 2013). The posteriolateral spines of marrellids may have formed from similar anlagen, in which case the serrated postero-lateral spines of Marrella and the serrated carapace margin of Skania may serve as another character linking these taxa.

\section{Supplementary data}

Appendix A - character list (www.geology.cz/bulletin/ supplement/1532_Legg\%20_APP_A.pdf).

Appendix B - supporting information for the phylogenetic analysis (www.geology.cz/bulletin/supplement/1532_Legg _APP_B.txt).

\section{Acknowledgements}

Thanks go to J.-B. Caron and P. Fenton, both at the Royal Ontario Museum, Toronto (ROM), and D.H. Erwin, at the National Museum of Natural Sciences, Smithsonian Institute, Washington DC (USNM). Additional thanks to J.-B. Caron and N. Woods (ROM) for providing additional photographs of Skania fragilis, plus G. Edgecombe, R. Lerosey-Aubril, and C. Wirkner, for helpful discussion. Thank you to Peter Van Roy and Diego García-Bellido for helpful reviews.

\section{References}

Bengtson, S. 2000. Teasing fossils out of shale with cameras and computers. Palaeontologia Electronica 3(4), 1-14.

Beurlen, K. 1930. Vergleichende Stammesgeschichte Grundlagen, Methoden, Probleme unter besonderer Berücksichtigung der höheren Krebse. Fortschritte er Geologie und Paläontologie 8, 317-586.

Conway Morris, S. 1993. Ediacaran-like fossils in Cambrian
Burgess Shale-type faunas of North America. Palaeontology 36, 593-635.

CRABb, P. 2001. The use of polarised light in photography of macrofossils. Palaeontology 44, 659-664.

DOI 10.1111/1475-4983.00196

Delle Cave, L. \& Simonetta, A.M. 1975. Notes on the morphology and taxonomic positon of Aysheaia (Onychophora?) and of Skania (indetermined phylum). Monitore Zoologico Italiano 9, 67-81.

DzIK, J. 2002. Possible ctenophoran affinities of the Precambrian "Sea-Pen" Rangea. Journal of Morphology 252, 315-334. DOI 10.1002/jmor.1108

García-Bellido, D.C. \& Collins, D. 2006. A new study of Marrella splendens (Arthropoda, Marrellomorpha) from the Middle Cambrian Burgess Shale, British Columbia, Canada. Canadian Journal of Earth Sciences 43, 721-742. DOI 10.1139/e06-012

Gehling, J.G. 1991. The case for Ediacaran fossil roots to the metazoan tree, 181-223. In RADHAKRISHNA, B.P. (ed.) The world of Martin F. Glaessner. Geological Society of India, Bangalore.

Glaessner, M.F. 1980. Parvancorina - an arthropod from the late Precambrian of South Australia. Annalen des Naturhistorischen Museums in Wien 83, 83-90.

GolobofF, P.A. 1999. Analysing large data sets in reasonable times: solutions for composite optima. Cladistics 15, 415-428. DOI 10.1111/j.1096-0031.1999.tb00278.x

GolobofF, P.A., Farris, J.S. \& Nixon, K.C. 2008. TNT, a free program for phylogenetic analysis. Cladistics 24, 774-786. DOI 10.1111/j.1096-0031.2008.00217.x

Harrington, H.J. 1968. General description of Trilobita, O38-O117. In Moore, R.C. (ed.) Treatise on invertebrate paleontology. Part O. Arthropoda. Vol. 1. Geological Society of America \& University of Kansas Press, Lawrence.

Haug, J.T., MaAs, A. \& WaloszeK, D. 2010. †Henningsmoenicaris scutula, $\dagger$ Sandtorpia vestrogothiensis gen. et sp. nov. and heterochronic events in early crustacean evolution. Earth and Environmental Science Transactions of the Royal Society of Edinburgh 101, 1-39.

DOI 10.1017/S1755691010008145

Hou, X.G. \& Bergström, J. 1997. Arthropods from the Lower Cambrian Chengjiang fauna, Southwest China. Fossils and Strata 45, 1-116.

Hou, X.G., RAmSkÖLD, L. \& BergStröm, J. 1991. Composition and preservation of the Chengjiang fauna - a Lower Cambrian soft-bodied biota. Zoologica Scripta 20, 395-411. DOI 10.1111/j.1463-6409.1991.tb00303.x

Hughes, C.P. 1975. Redescription of Burgessia bella from the Middle Cambrian Burgess Shale, British Columbia. Fossils and Strata 4, 415-435.

Hupé, P. 1953. Classification des trilobites. Annales de Paléontologie 39, 59-168.

Ivantsov, A.Y. 2001. Vendia and other Precambrian "arthropods". Paleontological Journal 35, 335-343.

KÜHL, G., Bergström, J. \& Rust, J. 2008. Morphology, palaeobiology and phylogenetic position of Vachonisia rogeri (Arthropoda) from the Lower Devonian Hunsrück Slate (Germany). Palaeontographica, Abteilung A 286, 123-157. 
Lee, M.S.Y., Soubrier, J. \& Edgecombe, G.D. 2013. Rates of phenotypic and genomic evolution during the Cambrian explosion. Current Biology 23, 1889-1895.

DOI 10.1016/j.cub.2013.07.055

LegG, D.A., Sutton, M.D. \& Edgecombe, G.D. 2013. Arthropod fossil data increase congruence of morphological and molecular phylogenies. Nature Communications 4(2485), 1-7. DOI 10.1038/ncomms3485

LegG, D.A., Sutton, M.D., Edgecombe, G.D. \& Caron, J.-B. 2012. Cambrian bivalved arthropod reveals origin of arthrodization. Proceedings of the Royal Society B 279, 4699-4704. DOI 10.1098/rspb.2012.1958

Lehmann, W.M. 1955. Vachonia rogeri n. g. n. sp., ein Branchiopod aus dem unterdevonischen Hunsrückschiefer. Paläontologische Zeitschrift 29, 126-130.

DOI 10.1007/BF03041794

Lin, J.P., Gon III, S.M., Gehling, J.G., BabCock, L.E., ZhaO, Y.L., Zhang, X.L., Hu, S.X., Yuan, J.L., Yu, M.Y. \& Peng, J. 2006. A Parvancorina-like arthropod from the Cambrian of South China. Historical Biology 18, 33-45. DOI 10.1080/08912960500508689

Naimark, E.B. \& Ivantsov, A.Y. 2009. Growth variability in the Late Precambrian problematic Parvancorina Glaessner. Paleontontological Journal 43, 12-18. DOI 10.1134/S003103010901002X

Nixon, K.C. 1999. The Parsimony Ratchet, a new method for rapid parsimony analysis. Cladistics 15, 407-414. DOI 10.1111/j.1096-0031.1999.tb00277.x

OLESEN, J. 2013. The crustacean carapace: morphology, function, development, and phylogenetic history, 103-139. In Watling, L. \& Thiel, M. (eds) The Natural History of Crustacea. Vol. 1. Oxford University Press.

Olesen, J. \& Møller, O.S. 2014. Notostraca, 40-46. In Martin, J.W., OlesEn, J. \& HøeG, J.T. (eds) Atlas of crustacean larvae. John Hopkins University Press, Baltimore.

Ortega-HernándeZ, J. \& Brena, C. 2012. Ancestral patterning of tergite formation in a centipede suggests derived mode of trunk segmentation in trilobites. PLoS One 7(12), 1-19. DOI 10.1371/journal.pone.0052623

RaK, Š., ORTEGA-HeRnÁndeZ, J. \& LegG, D.A. 2013. A revision of the Late Ordovician marrellomorph arthropod Furca bohemica from Czech Republic. Acta Palaeontologica Polonica 58, 615-628.

Rota-Stabelli, O., Daley, A.C. \& Pisani, D. 2013. Molecular timetrees reveal a Cambrian colonization of land and a new scenario for ecdysozoan evolution. Current Biology 23, 392-398. DOI 10.1016/j.cub.2013.01.026

SCHAARSCHMidT, F. 1973. Pflanzenfossilien in ungewöhnlichen Licht. Natur und Museum 103, 247-253.

Schram, F.R. \& Koenemmann, S. 2004. Are the crustaceans monophyletic?, 319-329. In Cracraft, J. \& Donoghue, M.J. (eds) Assembling the tree of life. Oxford University Press, New York.

Simonetta, A.M. \& Delle Cave, L. 1981. An essay in the comparative and evolutionary morphology of Palaeozoic arthropods. Origine dei grandi Phyla dei Metazoi. Accademia Nazional dei Lincei, Atti dei Convegni Lincei 49, 389-439.

SimonetTA, A.M. \& Insom, E. 1993. New animals from the Burgess Shale (Middle Cambrian) and their possible significance for the understanding of the Bilateria. Bolletino di Zoologia 60, 97-107. DOI 10.1080/11250009309355797

Siveter, D.J., Briggs, D.E.G., Siveter, D.J., Sutton, M.D., LEGG, D. \& JoOmun, S. 2014. A Silurian short-great-appendage arthropod. Proceedings of the Royal Society B 281 (in press). DOI 10.1098/rspb.2013.2986

Siveter, D.J., Fortey, R.A., Sutton, M.D., Briggs, D.E.G. \& SivETER, D.J. 2007. A Silurian 'marrellomorph' arthropod. Proceedings of the Royal Society B 274, 2223-2229. DOI 10.1098/rspb.2007.0712

STøRMER, L. 1944. On the relationships and phylogeny of fossil and Recent Arachnomorpha. Skrifter utgitt av det Norske Vidensk Academi i Oslo 5, 1-158.

StÜRmer, W. \& Bergström, J. 1976. The arthropods Mimetaster and Vachonisia from the Devonian Hunsrück Shale. Paläontologische Zeitschrift 50, 78-111. DOI 10.1007/BF03001974

TASCH, P. 1969. Branchiopoda, R128-R191. In Moore, R.C. (ed.) Treatise on invertebrate paleontology. Part R. Arthropoda Vol 4(1). Geological Society of America and University of Kansas Press, Lawrence.

Van Roy, P., Orr, P.J., Botting, J.P., Muir, L.A., Vinther, J., Lefebvre, B., el Hariri, K. \& Briggs, D.E.G. 2010. Ordovician faunas of Burgess Shale-type. Nature 465, 215-218. DOI 10.1038/nature09038

VANNIER, J. \& ChEn, J.Y. 2002. Digestive system and feeding mode in Cambrian naraoiid arthropods. Lethaia 35, 107-120. DOI 10.1080/002411602320183971

WAGGONER, B.M. 1996. Phylogenetic hypotheses of the relationships of arthropods to Precambrian and Cambrian problematic fossil taxa. Systematic Biology 45, 190-222. DOI 10.1093/sysbio/45.2.190

WaLcotT, C.D. 1931. Addenda to descriptions of Burgess Shale fossils. Smithsonian Miscellaneous Collections 85, 1-46.

Wills, M.A., Briggs, D.E.G., Fortey, R.A., Wilkinson, M. \& SNEATH, P.H.A. 1998. An arthropod phylogeny based on fossil and recent taxa, 33-105. In Edgecombe, G. (ed.) Arthropod fossils and phylogeny. Columbia University Press, New York.

Zhang, X.L., Han, J., Zhang, Z.F., Liu, H.Q. \& Shu, D.G. 2003. Reconsideration of the supposed naraoiid larva from the Early Cambrian Chengjiang Lagerstätte, South China. Palaeontology 46, 447-465. DOI 10.1111/1475-4983.00307 